\title{
Impact of Vulnerable Group Development (VGD) program on Improvement of Woman Headed Household Consumption Diversity in Bangladesh
}

\author{
Mohammad Abdul Hannan Pradhan ${ }^{1}$, Jamalludin Sulaiman,2 \\ 1 Department of Economics, Shahjalal University of Science and Technology, Sylhet, Bangladesh. Email: \\ hannan-eco@sust.edu \\ 2 School of Social Science, Universiti Sains Malaysia, Penang, Malaysia, Email: jamals@usm.my
}

\begin{abstract}
A number of studies have established that Vulnerable Group Development (VGD) program beneficiaries are better off during the two-year benefit cycle. This study was an attempt to provide evidence using household survey data on whether the VGD program improves beneficiary household welfare over the cycle. This study was conducted in Sylhet district of Bangladesh. A structured questionnaire was administered to collect data from equal number of beneficiary and nonbeneficiary households. This study used the propensity score matching (PSM) method to analyse data. The study finds a robust and positive effect of program on the beneficiary households to improve their wellbeing through improving meal frequency, per capita expenditure. The results signify consumption variability of the beneficiaries' households. Furthermore, this behaviour of beneficiaries increases the demand for different items of good at the local market which could help enhancing the national growth. Thus the number of program beneficiary could be increased to promote the process.
\end{abstract}

\section{Keywords}

Women headed household, Social safety net; Propensity scores matching; Consumption variability

\section{INTRODUCTION}

Bangladesh has accomplished a stable improvement in increasing real GDP growth at approximately five percent during more than two decades since 1990s (FD, 2011). Though the growth rate of real GDP is about five percent, it has not trickled down to the bottom level of the society (Gentilini \& Webb, 2008). Consequently, they suffer from insufficient income or consumption, poor health condition, low productivity of labour, poor housing condition, and others. Among the poor, women are more vulnerable particularly in the rural areas. Women or woman headed families suffer from discrimination because of their sex, limited earning capacities and opportunities; and limited access to markets, education and nutritional intake. As a result, they lead their life in the lower level of well being in the society (Sheheli, 2012).

The government has implemented a number of Social Safety Net (SSN) programs to protect the targeted underprivileged population such as the Old Age Allowance (for elderly), the Widow Allowance (for vulnerable women), Work For Food and 100 Days Employment Project (for the young unemployed). The two-year Vulnerable Group Development (VGD) program is the largest SSN program that provides in-kind transfer with development programs for selected women-headed poor family (between 18-50 years) to surmount existing food insecurity, malnutrition, and lower social status. A number of studies have established that VGD beneficiaries are better off during the two-year benefit cycle (Afrad, Ferdous, Muttaleb, \& Rahman, 2012; Ahmed, Quisumbing, Nasreen, Hoddinott, \& Bryan, 2009; Matin \& Hulme, 2003; Ninno \& Dorosh, 2003; Rhman \& Choudhury, 2012). The program benefit help increase food consumption initially. Food consumption and income capacity are positively related (Rosenzweig, 1988). To continue or increase the consumption diversity after the benefit cycle would be a critical question. This situation might imply the beneficiaries' better off condition due to the persistent income capacity.

This paper offers evidence from a micro level household survey data on whether the VGD program contributes to increase the consumption variability for the targeted households at the end of the benefit cycle. Per capita household expenditure consisting food and non-food and meal frequency were used as outcome indicators. The PSM method was employed to examine the program impact on the targeted variables. At the same time, Simpson Index (SI), known as diversity index, is used to show the robustness of the findings.

\section{Description of the program}

After independence in 1971, the government have taken several steps to improve the socio economic condition of rural poor women by implementing various programs including SSN program. The VGD program is one of the largest SSN programs that provide in-kind transfer with development programs for two years for selected women-headed poor family who are sound physically as well as mentally. It is argued that in-kind transfers protect the beneficiary household from hardcore poverty in one hand. On the other hand, development training promotes their livelihood condition through productive activities. As a result, it is expected that after the benefit cycle the beneficiary household will be able to survive in a good condition without benefit. This is also an opportunity for women headed household to promote their livelihood condition persistently.

Under the VGD program, the selected women headed household receives a monthly food ration (30 kg rice) over a period of 24 months cycle. Basically it was introduced as a relief program in the mid-1970s. Now it has progressed to integrate food security with development objectives including training on income generating activities like livestock rearing, vegetable gardening and awareness-raising on social, legal, and health and nutrition issues. The key object of VGD 
program is to assist the poor rural women headed family to overcome existing food insecurity, malnutrition, lower social status and poverty so that the people can live without ultra poor condition.

\section{Methodology: Study Are, Data Colletion Technique and Analytical Tools}

This study was carried out in Sylhet district in Sylhet division situated in the north east corner of Bangladesh. Among four districts, Sylhet district is the largest among four administrative districts which comprises twelve Upazila and 101 unions. Total area of land is about 3,490 square kilometres where 3404 thousand people are living. Infrastructures of this district have been rapidly developing for more than a decade. These areas are well connected each other and to the other part of the country by road. Domestic works, petty trading, agricultural, off firm activities like construction, day labourer and others are the main sources of livelihood to the poor women.

This study used cross section data which were collected through a field survey of 317 households. Total numbers of sample was divided into two groups, program participant, VGD beneficiaries, and nonparticipant, eligible for the program but did not select for the program. As the government selects a number of vulnerable and poor women for transferring VGD program benefit for two year cycle, beneficiary households were selected for this study from the list for 2010-2011 year cycle ended in December, 2012. For the comparison, control group was chosen from the same region considering pre-intervention criterion. According to the government regulation, only 50 households are selected from a union every year. However, the reason for choosing the non-beneficiary households from same region is that both groups compete for the same economic inducement and access to similar markets (Ravallion, 2007). Khandker, Koolwal, and Samad (Khandker, Koolwal, \& Samad, 2010) argued that to improve the accuracy of the propensity score, the larger number of nonparticipants compare to participants is essential. Jalan and Ravallion (Jalan \& Ravallion, 2003) asserts that for dependable program effects, beneficiaries and non-beneficiaries should be the same number.

This study applied three-stage sampling technique for selecting targeted respondents. As the VGD program is implemented throughout the country, Sylhet distric was purposively selected for convenience. At first, based on poverty criterion twelve Upazzilla was divided into three strata. From every stratum, one Upazzilla was chosen randomly namely Sylhet Sadar, Jaintapur, and Fulbari. Two unions were chosen from each selected Upazzila randomly. In the end, equal number of beneficiaries and non-beneficiaries were chosen randomly based on their availability in the house on the survey date. A structured questionnaire was administered for the both beneficiaries and non-beneficiaries households in this study. Questionnaire was designed based on the household income expenditure survey questionnaire-2005 used by Bangladesh Bureau of Statistics (BBS) including demographic characteristics, housing condition, land holding, household expenditure (food and non-food). The questionnaire was pre-tested and final field survey was conducted in January and February 2013.

\section{Construction of the outcome variables}

\section{Data analysis}

This study applied PSM method to estimate the average treatment effect (ATT) based on outcome variables. The PSM method is known as nonrandomized and non-parametric approach for impact evaluation. Thus, the study relied on the PSM method to identify comparable program beneficiary and non-beneficiary households using cross section data. This method provides consistent, low-bias estimates of program impact if: (1) the same data source such as same questionnaire, same time, and same interviewer are used for beneficiary and non-beneficiary, (2) beneficiary and nonbeneficiary have access to same markets, and (3) limited number of observe characteristics is included (Heckman, Ichimura, \& Todd, 1998; Jalan \& Ravallion, 2003; Khandker, et al., 2010).

The basic evaluation technique based on observed outcomes variables across participant and non-participant in the program, for instance per capita expenditure, $\mathrm{E}$ of an individual household $i$ is presented as: $\mathrm{E}_{i}=\alpha \mathrm{X}_{i}+\beta \mathrm{T}_{i}+\mu_{i}$

Where, $T$ is a dummy variable, which is equal to 1 for those who participate and 0 for those who do not participate in the VGD program. $X_{i}$ is the set of other observed characteristics of the household which determine the program participation. In addition, $\mu_{i}$ is an error term reflecting omitted characteristics of the household that also affect $\mathrm{E}$. Equation (1) notifies an approach commonly applied to evaluate the program impact, which is used to measure the direct effect of the program $\mathrm{T}$ on outcome $\mathrm{E}$. The problem with estimating equation (1) is that the providing program benefit was not random due to the following factors: a) program placement was purposive; especially for poor and vulnerable women head household and b) mean tested selection procedure was employed for beneficiary selection into the program.

It assumes that data include an observation of $\mathrm{E}_{i}$ for each unit $i$ in a sample of size $\mathrm{n}$. Some unit received the program benefits, in which case they were treated as "beneficiary" and in that case $\mathrm{T}_{i}=1$, while $\mathrm{T}_{i}=0$ when "control group", which was not VGD benefit holder. The value of $\mathrm{E}_{i}$ for participant is denoted $\mathrm{E}_{i}^{1}$ while it is $\mathrm{E}_{i}^{0}$ for nonparticipant or control group. If the $\mathrm{E}_{i}^{0}$ indicates non-participating household at the same time as a comparison benefit for participating benefits $E_{i}^{1}$, the average treatment effect (ATE) of the program $(\Pi)$ could be as follows: 
The participant and nonparticipant groups may not be the same prior to the intervention, so the expected difference between those groups may not only be due to the program intervention. Adding and subtracting the expected outcome for non-participants if they had participated in the program, the equation (2) could be as follows:

$$
\begin{gathered}
\Pi=\mathrm{E}\left(\mathrm{E}_{i}^{1} / \mathrm{T}_{i}=1\right)-\mathrm{E}\left(\mathrm{E}_{i}^{0} / \mathrm{T}_{i}=0\right)+\left[\mathrm{E}\left(\mathrm{E}_{i}^{0} / \mathrm{T}_{i}=1\right)-\mathrm{E}\left(\mathrm{E}_{i}^{0} / \mathrm{T}_{i}=0\right)\right] \\
=A T E+\left[\mathrm{E}\left(\mathrm{E}_{i}^{0} / \mathrm{T}_{i}=1\right)-\mathrm{E}\left(\mathrm{E}_{i}^{0} / \mathrm{T}_{i}=0\right)\right. \\
=A T E+\Omega
\end{gathered}
$$

In the equation (3), ATE is the average treatment effect, specifically the average gain in benefit of participant compared with non-participant as if non-participating household were participated. The ATE corresponds to a situation in which an arbitrarily selected household from the population was assigned to the program, so participating and non-participating households have an equal probability of receiving program benefit, $\mathrm{T}$.

The term $\Omega$ in the equation (3), as $\mathrm{E}\left(\mathrm{E}_{i}^{0} / \mathrm{T}_{i}=1\right)$ is not available to estimate, the magnitude of selection bias $(\Omega)$ cannot be calculated. As a result, the difference in outcome between participant and non-participant could not be estimated (Khandker et al., 2009). To get rid of this biasness, PSM method is commonly used. The PSM method attempts to estimate program effect across participants and matched nonparticipant based on a range of observed characteristics (Galasso \& Ravallion, 2005). This idea was applied to find those who are observationally similar to participant in terms of characteristics. Based on the observationally similar characteristics, program participants can be matched with the nonparticipants. The mean differences in the outcome variables across the groups are compared as treatment effect. Khandker et al. (2009) mentioned that if the differences in participation and nonparticipation are based only on the differences in observered characteristics, and a larger number of nonparticipants are available to match with participants, the corresponding program impact can be estimated even if the program is not random.

In terms of many observe characteristics, two households can be similar in many dimensions or rarely similar. In PSM method, participant in the program is matched to nonparticipant based on a single propensity score. It indicates that participants are matched based on the estimated probability, or propensity score, to nonparticipants. Then ATE is calculated as the mean difference in outcomes across these two groups (Rosenbaum \& Rubin, 1983). For that reason, two basic assumptions are required to be fulfilled for credentials the program effect. First, conditional independence $(\mathrm{Cl})$ which states that given a set of observable covariates $X$ that are not affected by program; outcomes $Y$ are independent of program assignment $\mathrm{T}$. This implies that program placement is fully based on observed characteristics of the households. The region of common support (CS) or overlap is the second assumption which indicates: $0<P\left(\mathrm{~T}_{i}=1 \mid \mathrm{X}_{i}\right)<1$. Heckman, LaLonde, and Smith (Heckman, LaLonde, \& Smith, 1999) mentioned that the CS condition makes sure that the participant observations have comparison observation in the distribution of propensity score. Particularly, the efficiency of the PSM technique requires a large and equal number of participant and nonparticipant observation. Hence, a considerable CS region can be found.

If $\mathrm{Cl}$ and $\mathrm{CS}$ condition are satisfied as mentioned earlier, the PSM estimator is useful to estimate ATE as mean differences in outcome variables weighting the nonparticipants in the program by propensity score of participants in the program. $A$ standard cross-section estimator can be specified following way in equation (4):

$$
A T E_{p s m}=E_{p(X) / T=1}\left\{E\left[\mathrm{E}^{T} T=1, P(X)\right]-E\left[\mathrm{E}^{C} \mid T=0, P(X)\right]\right\}
$$

However within the common support for cross-sectional data, the treatment effect can be written as follows in equation (5) as mention by Heckman, Ichimura, and Todd (1997) and Khandker et al. (2009).

$$
A T E_{P S M}=\frac{\left[\sum_{i \in T} \mathrm{E}_{i}^{T}-\sum_{j \in C} \omega(i, j) \mathrm{E}_{j}^{C}\right]}{\mathrm{N}_{T}}
$$

where $\mathrm{N}_{T}$ is the number of participants $i$ and $\omega(i, j)$ is the weight used to aggregate outcomes for the matched nonparticipants $j$. After proper matching, biasness is removed $(\Omega=0)$. Then $\Pi=A T E$ is found (Khandker et al., 2009).

The PSM method has been applied to assess the program impact in different countries. For instant, Abebaw, Fenti, and Kassa (Abebaw, Fentie, \& Kassa, 2010) evaluated the impact of a food security program on household consumption in the Northwester Ethiopia. Raza and Ara (Raza \& Ara, 2012) estimated the Challenging the Frontires of Poverty Reduction (CFPR) program impact on beneficiary households' livelihoods in Bangladesh. Jalan and Ravallion (2003) assessed the effect on benefit incidence of an anti-poverty program in Argentina. Mendola (Mendola, 2007) calculated the impact of

\section{P a g e}


agricultural technology adoption on poverty reduction in Bangladesh. Hope (Hope, 2007) applied PSM method to estimate the social impacts on a watershed development program in India.

To calculate the VGD program effect, the samples of beneficiary and non-beneficiary groups were pooled. Then by fitting logit model in terms of common variables as shown in Table 1, an individual household probability to be included in the VGD program was estimated. Common characteristics of households were considered as explanatory variables, in another way intervening variables, presented in Table 1. After the participation equation estimation, the predicted values of the probability of participation $\mathrm{T}$ were calculated. The predicted results signify the estimated probability to the program or propensity score. Subsequently, the common support region was defined where the distributions of the propensity score for participant and nonparticipant groups overlapped. If nonparticipant observations fall outside the common support region, they are dropped. Then special matching criteria applied to assign program participants to nonparticipants based on estimated propensity score.

Hence, it is required to calculate a weight for every matched participant-nonparticipant group. There are several methods to assign weight such as Nearest-neighbour matching (NNM), radius matching (RM), stratified matching (SM), kernel matching $(\mathrm{KM})$. In the NNM, each participant is matched to the nonparticipant with the nearest propensity score as measured by the absolute difference in score. The RM imposes a threshold on the maximum propensity score distance. The SM divides the common support into different strata and estimates the impact of a program within each stratum. A weighted mean of these strata impact estimates comply the overall program impact. The KM employs a weighted average of every non-participant to make the counterfactual match for every participant. However, to compare the results across alternatives matching methods may reveal whether the estimated program effect is robust. Finally, ATE were estimated as the mean difference in outcomes over the common support, weighting the nonparticipants by the propensity score distribution of the program beneficiaries as shown in equation (5).

Maintaining the above mentioned way, particularly in equation (5), ATE for protection such as per capita expenditure, food expenditure, non-food expenditure were estimated. For the promotion effect, net savings, asset creation such as durable and productive, petty investment were calculated. Average difference of probability being poor between beneficiary and non-beneficiary households was estimated as recommended by Angrist (Angrist, 2001). Descriptive statistics were applied to analysis child schooling for both groups.

Table 1: Notation, Name and Description of Explanatory Variables

\begin{tabular}{|l|l|l|}
\hline Variable & Types and definition & measurement \\
\hline variable & & \\
\hline Participant & Dummy, involvement in VGD program & 1 if yes, 0 otherwise \\
\hline $\begin{array}{l}\text { Independent } \\
\text { variables }\end{array}$ & & \\
\hline Age & age of household head & \\
\hline Member & family size & Years completed \\
\hline Land & land holding by the household & Decimal \\
\hline Mdisable & Dummy, married with disable husband & 1 if disable husband, 0 otherwise \\
\hline Widowed & Dummy, household head widowed & 1 if widowed, 0 otherwise \\
\hline Deserted & Dummy, household head deserted & 1 if deserted, 0 otherwise \\
\hline Divorced & Dummy, household head divorced & 1 if divorced, 0 otherwise \\
\hline Unmarried & Dummy, household head unmarried & 1 if unmarried, 0 otherwise \\
\hline Housing & Dummy, living condition & 1 if live in own house, 0 otherwise \\
\hline
\end{tabular}

\section{Results and discussion}

\subsection{Background of the Respondents}

This study targeted the VGD program to measure its impact on household welfare, specifically improving consumption diversity. Care was taken to ensure the representation of beneficiary households from the selected area. Around 50 percent of beneficiaries were taken as a sample from the targeted area and equal number of non-beneficiary was also chosen from same targeted areas. The same questionnaire was administered for beneficiary and non-beneficiary interview at the same time by the same researcher. The socio-demographic variables that appeared in this study are household type, gender, age, marital status, education level, and family size.

Table 2 indicates that all respondents for the interview were about equally divided into beneficiary (49.8\%) and nonbeneficiary $(50.2 \%)$. All respondents were female as the program targeted the female headed households. The lists of beneficiaries collected from the local administrative office also support this criterion. A large portion of the respondents 
$(40.73 \%)$ was widowed. Meanwhile, about 35.3 percent was currently married with disable husband. The rest of the respondents were either deserted by their husband (12.6\%), divorce $(6.6 \%)$, or unmarried $(4.4 \%)$. Most of the respondents were illiterate $(69.7 \%)$, and a small portion $(20.2 \%)$ could only sign their name only. Table 2 also shows that the majority of the respondents were between 31 to 40 years old. The figures indicate that 11.35 percent and 26.81 percent of the respondents were between 18-30 and 41-50 respectively, while 61.83 percent were between 31-40 years.

Rural women between 31-40 years old fall into vulnerable positions due to divorce, deserted or widowed. At this stage, most of them were young. Consequently, assistances were provided to cope up with the prevailing situation. Receiving food transfers with development training, it was argued that household also could use to put their skills into concrete use. But for the older, another kind of assistance provided such as an old age allowance, widowed and destitute allowance. Moreover, respondents tended to have a smaller household as the results pointed out that 31.55 percent and 53.31 percent of the respondents had household sizes between 1-3 and 4-5 member, respectively.

Table 2: Demographical profile of the survey respondents

\begin{tabular}{|c|c|c|c|c|}
\hline & Items & Freq & Percent & Cum \\
\hline Household Type & $\begin{array}{l}\text { Beneficiary } \\
\text { Non-beneficiary } \\
\text { All }\end{array}$ & $\begin{array}{l}158 \\
159 \\
317\end{array}$ & $\begin{array}{l}49.8 \\
50.2 \\
100\end{array}$ & $\begin{array}{l}49.8 \\
100\end{array}$ \\
\hline Age & $\begin{array}{l}18-30 \\
31-40 \\
41-50\end{array}$ & $\begin{array}{l}36 \\
196 \\
85\end{array}$ & $\begin{array}{l}11.35 \\
61.83 \\
26.81\end{array}$ & $\begin{array}{l}11.35 \\
73.18 \\
100\end{array}$ \\
\hline Gender & $\begin{array}{l}\text { Female } \\
\text { Male }\end{array}$ & $\begin{array}{l}317 \\
0\end{array}$ & $\begin{array}{l}100 \\
0\end{array}$ & $\begin{array}{l}100 \\
0\end{array}$ \\
\hline Marital Status & $\begin{array}{l}\text { Married } \\
\text { Married with disable husband } \\
\text { Divorced } \\
\text { Deserted } \\
\text { Widow } \\
\text { Unmarried }\end{array}$ & $\begin{array}{l}01 \\
112 \\
21 \\
40 \\
129 \\
14\end{array}$ & $\begin{array}{l}0.3 \\
35.3 \\
6.6 \\
12.6 \\
40.7 \\
4.4\end{array}$ & $\begin{array}{l}0.3 \\
35.6 \\
42.3 \\
54.9 \\
95.6 \\
100\end{array}$ \\
\hline Household Size & $\begin{array}{l}1 \text { to } 3 \\
4 \text { to } 5 \\
6 \text { and above }\end{array}$ & $\begin{array}{l}100 \\
169 \\
48\end{array}$ & $\begin{array}{l}31.55 \\
53.31 \\
15.14\end{array}$ & $\begin{array}{l}31.55 \\
84.85 \\
100\end{array}$ \\
\hline Education Level & $\begin{array}{l}\text { Illiterate } \\
\text { Sign only } \\
\text { Read only } \\
\text { Read and write } \\
\text { Primary }\end{array}$ & $\begin{array}{l}221 \\
64 \\
02 \\
16 \\
14\end{array}$ & $\begin{array}{l}69.7 \\
20.2 \\
0.6 \\
05 \\
4.4\end{array}$ & $\begin{array}{l}69.7 \\
89.9 \\
90.5 \\
95.6 \\
100\end{array}$ \\
\hline
\end{tabular}

Source: Calculate by author from survey data

Table 3 and 4 present the demographic profile of the beneficiary and non-beneficiary households, respectively. In the both groups, all respondents were female. Among the respondents, 51.27 percent and 62.89 percent in the age group $31-40$ were the beneficiary and non-beneficiary, respectively. Considering the marital status, 44.93 percent and 39.24 percent were married with disable husband and widowed among the beneficiaries, respectively.

Similarly, this rate was 25.78 and 42.13 percent among the non-beneficiary household. It can be mentioned that 19.50 percent of the non-beneficiary was deserted by their husbands. Considering the educational level, most of the respondents, whether the beneficiary $(61.39 \%)$ or non-beneficiary $(77.36 \%)$, were illiterate. The size of household tended to concentrate between 4 to 5 of the beneficiaries $(51.9 \%)$ and non-beneficiaries $(54.71 \%)$. 
Table 3: Demographical profile of the beneficiary respondents

\begin{tabular}{|l|l|l|l|l|}
\hline & Items & Freq & Percent & Cum \\
\hline Age & $18-30$ & 31 & 19.62 & 19.62 \\
& $31-40$ & 81 & 51.27 & 70.88 \\
& $41-50$ & 46 & 29.11 & 100 \\
\hline Gender & Female & 158 & 100 & 100 \\
& Male & 00 & 00 & 00 \\
\hline Marital Status & Married & 00 & 00 & 00 \\
& Married with disable husband & 71 & 44.93 & 44.93 \\
& Divorced & 07 & 4.43 & 49.36 \\
& Deserted & 09 & 5.69 & 55.05 \\
& Widow & 62 & 39.24 & 94.29 \\
& Unmarried & 09 & 5.71 & 100 \\
& & & & \\
\hline Household Size & 1 to 3 & 37 & 23.41 & 23.41 \\
& 4 to 5 & 82 & 51.90 & 75.30 \\
& 6 and above & 39 & 24.69 & 100 \\
& Illiterate & 97 & 61.39 & 61.39 \\
& Sign only & 39 & 24.68 & 86.07 \\
& Read only & 02 & 1.27 & 87.35 \\
& Read and write & 11 & 6.97 & 94.31 \\
& Primary & 08 & 5.69 & 100 \\
& & & & \\
\hline
\end{tabular}

Source: Calculate by author from survey data

Table 4: Demographical profile of the non-beneficiary respondents

\begin{tabular}{|l|l|l|l|l|}
\hline & Items & Freq & Percent & Cum \\
\hline Age & $18-30$ & 20 & 12.58 & 12.58 \\
& $31-40$ & 100 & 62.89 & 75.47 \\
& $41-50$ & 39 & 24.53 & 100 \\
\hline Gender & Female & 159 & 100 & 100 \\
& Male & 00 & 00 & 00 \\
\hline Marital Status & Married & 01 & 0.63 & 0.63 \\
& Married with disable husband & 41 & 25.78 & 26.42 \\
& Divorced & 14 & 8.81 & 35.22 \\
& Deserted & 31 & 19.50 & 54.72 \\
& Widow & 67 & 42.13 & 96.86 \\
& Unmarried & 05 & 3.14 & 100 \\
\hline Household Size & 1 to 3 & 63 & 39.62 & 39.62 \\
& 4 to 5 & 87 & 54.71 & 94.33 \\
& 6 and above & 09 & 5.67 & 100 \\
\hline Education Level & Illiterate & 123 & 77.36 & 77.36 \\
& Sign only & 25 & 15.72 & 93.08 \\
& & & & \\
\hline
\end{tabular}




\begin{tabular}{|l|l|l|l|l|}
\hline & Read only & 00 & 00 & 93.08 \\
& Read and write & 05 & 3.14 & 96.22 \\
& Primary & 06 & 3.78 & 100 \\
\hline
\end{tabular}

Source: Calculate by author from survey data

\subsection{Descriptive Statistics Based on Selection Criterion for the Program Participation}

Descriptive statistics for the VGD beneficiary and non-beneficiary surveyed households were presented in Table 5 based on the selection criterion which can be mention as pre-intervention characteristics. The average age of household head was about 37 years. In particular, the average age of participant and non-participant household heads were 36.91 and 37.06 years, respectively. The difference in means of age was very insignificant $(t=0.227)$. These results indicate that both groups were young and able to do productive work. Specifically, the respondents whether beneficiary or nonbeneficiary were those women who had the ability to learn and could appoint themselves in income generating activities.

On the household size, the average number of household member was 4.16 for all respondents. The number of family member in beneficiary household was higher than the number of family members in non-beneficiary household and the difference in mean of family members was significant at the 1 percent level $(t=-6.201)$. The mean value of married with disable husband (MarriedDisH) was 0.353 for the respondents. Among beneficiary and non-beneficiary households, the mean values were 0.449 and 0.257 , respectively. The mean difference was also significant at the 1 percent level $(t=-$ 3.628). This difference implies that after selecting for the program cycle in a particular area based on this criterion the number of eligible household is the smaller amount.

The mean value for widowed was 0.407 . The mean value for beneficiary and non-beneficiary were 0.392 and 0.421 , respectively. The mean difference was not significantly different. The mean value for Deserted was 0.126 which is close to 0 meaning that the less number of respondent from this category. The mean value for beneficiary and non-beneficiary respondent were 0.056 and 0.194 , respectively which was significantly difference at the 1 percent level.

Moreover, intervening criterion for participation in the program such as widowed, divorced, vulnerable unmarried women were same for the both groups. The main differences between the two groups of households were observed with respect to land size, married with disable husband, deserted, and housing condition.

The respondents were asked whether they had any homestead. About 23 percent replied that they had no land, even homestead. They lived in relative or others houses. On the other hand, 77 percent respondents lived in their own house. That indicates that they have homestead. Among the beneficiary, 87.34 percent had homestead while among the nonbeneficiary it was 66.66 percent. Average area of land holding by the beneficiary and non-beneficiary household was 3.32 and 2.33 decimal, respectively. This result was statistically significant at the 1 percent level $(t=-4.497)$. Though the mean difference is significant, the area of land holding was very small. This means that both groups were eligible for getting benefit in terms of the land holding criterion. In addition, almost all respondents used their land as homestead, not for agriculture or other productive purposes because of limited land holding.

Table 5: Descriptive statistics of sample households based on pre-intervention characteristics

\begin{tabular}{|c|c|c|c|c|c|c|c|c|c|}
\hline \multirow{3}{*}{$\begin{array}{l}\text { Variables } \\
\text { Age }\end{array}$} & \multicolumn{2}{|c|}{ Sample households } & \multicolumn{2}{|c|}{$\begin{array}{l}\text { Beneficiary } \\
\text { households }\end{array}$} & \multicolumn{2}{|c|}{ Non-beneficiary } & \multicolumn{2}{|c|}{ Difference in means } & \multirow{3}{*}{$\begin{array}{l}\text { t-value } \\
0.227\end{array}$} \\
\hline & \multicolumn{2}{|c|}{ Mean std.dev } & \multicolumn{2}{|c|}{ Mean std.dev } & \multicolumn{2}{|c|}{$\begin{array}{ll}\text { Mean } & \text { Std.dev }\end{array}$} & \multicolumn{2}{|c|}{$\begin{array}{ll}\text { Mean } & \text { std.err }\end{array}$} & \\
\hline & 36.99 & 6.174 & 36.91 & 6.70 & 37.06 & 5.618 & 0.168 & 0.694 & \\
\hline Member & 4.16 & 1.208 & 4.56 & 1.238 & 3.76 & 1.038 & 0.795 & -0.128 & -6.201 \\
\hline Land & 2.82 & 2.023 & 3.32 & 1.977 & 2.33 & 1.951 & 0.992 & -0.220 & -4.497 \\
\hline MarriedDisH & 0.353 & 0.478 & 0.449 & 0.499 & 0.257 & 0.438 & 0.191 & -0.052 & -3.628 \\
\hline Widowed & 0.407 & 0.492 & 0.392 & 0.489 & 0.421 & 0.495 & -0.029 & 0.055 & -0.523 \\
\hline Deserted & 0.126 & 0.332 & 0.056 & 0.232 & 0.194 & 0.397 & -0.138 & -0.036 & 3.770 \\
\hline Divorced & 0.066 & 0.249 & 0.044 & 0.206 & 0.088 & 0.284 & -0.043 & -0.028 & 1.56 \\
\hline Unmarried & 0.044 & 0.205 & 0.056 & 0.232 & 0.031 & 0.175 & 0.025 & -0.031 & -1.104 \\
\hline Housing & 0.697 & 0.461 & 0.829 & 0.377 & 0.566 & 0.497 & 0.263 & -0.049 & -5.302 \\
\hline
\end{tabular}

Note: $*, * *$ and $* * *$ indicated significant at $10 \%, 5 \%$ and $1 \%$ level, respectively

Source: Calculate by author from survey data 


\subsection{Results for the Logit Regression of Participation in the VGD Program}

The first step was to quantify the impact of VGD program; beneficiary and non-beneficiary household were polled. Then the participation equation into the program was estimated by using logit model to estimate the propensity score (equation 3.8 in chapter 3). For estimation, "pscore" command was used. This score implies the probability to be included in the VGD program of household. The estimated propensity score was required to mean that the covariates were exogenous and unaffected by the program. Selection criterions were considered to ensure this condition in this study. As the target group were poor woman, gender was not considered here. Other resources such as durable, nondurable, productive asset were not considered because program objectives were to increase these assets, income, and expenditure as well. Table 6 presents the estimated results of logit model for participation into the program. The estimated results show the significant influence to participate in the program with expected sign of coefficients to the key variables. The positive sign indicates the program association with intervening variable indicating the probability to be included in the program. The different characteristics increase the probability of receiving the VDG program including those who were widowed, deserted, divorced, unmarried, married with disable husband, have less areas of land, have large family size, and poor housing condition. The older female household head was less likely to receive the VGD benefit. It can be mentioned here that government provide old age allowance or destitute allowance for those who are 60 years or above. The estimated minimum Log-likelihood value of the model after iteration is -186.9407 . Psuedo- $R^{2}$ is 0.1492 and LR $\lambda^{2}$ value is 65.57 . These results imply that the model does not fit well. It is not required to fit the participation equation well. If it is required, it would be very difficult to identify non-participants who would be similar to participants (Haughton \& Khandker, 2009)(Haughton \& Khandker, 2009, pp. 261). Only based on this equation, propensity score is estimates for the region of common support.

Table 6: Logit results of household participation in the program

\begin{tabular}{|c|c|c|c|c|c|c|}
\hline Variable & Coefficient & Std.error & $z$ & $p>|z|$ & \multicolumn{2}{|c|}{ [95\% confidence interval] } \\
\hline Age & -0.0391 & 0.0248 & -1.58 & 0.115 & -0.0878 & 0.0095 \\
\hline Member & 0.4610 & 0.1294 & 3.56 & 0.000 & 0.2074 & 0.7147 \\
\hline Land & 0.0748 & 0.0838 & 0.90 & 0.366 & -0.0875 & 0.2372 \\
\hline MarriedDisH & 16.8358 & 1.0456 & 16.10 & 0.000 & 14.7862 & 18.8853 \\
\hline Widowed & 16.8101 & 1.0500 & 16.01 & 0.000 & 14.7521 & 18.8681 \\
\hline Deserted & 15.4444 & 0.9748 & 15.84 & 0.000 & 13.5336 & 17.3551 \\
\hline Divorced & 16.0986 & 0.9892 & 16.27 & 0.000 & 14.1596 & 18.0375 \\
\hline Unmarried & 17.0228 & 0.9869 & 17.25 & 0.000 & 15.0884 & 18.9573 \\
\hline Housing & $0.8147^{-1}$ & 0.3492 & 2.33 & 0.020 & 0.1302 & 1.4992 \\
\hline Constant & $-17.8828^{m-1}$ & 0.9476 & -17.32 & 0.000 & -14.0987 & 19.0879 \\
\hline \multicolumn{7}{|c|}{ Sample size(N) 317} \\
\hline \multicolumn{7}{|c|}{ Psuedo- $R^{2} \quad 0.1492$} \\
\hline \multicolumn{7}{|c|}{ LR $\lambda^{2}$ value $\quad 65.57^{* * *}$} \\
\hline \multicolumn{7}{|c|}{ Log-likelihood $\quad-186.9407$} \\
\hline
\end{tabular}

Note: ${ }^{*},{ }^{* *}$ and ${ }^{* \star *}$ indicated significant at $10 \%, 5 \%$ and $1 \%$ level, respectively

Source: Calculate by author from survey data

The estimated propensity scores using the logit model vary between 0.0503 and 0.8164 (mean $=0.4065$ ) for VGD nonbeneficiary and between 0.0728 and 0.9299 (mean $=0.5935)$ for beneficiary households. The region of common support has been selected between 0.0728 and 0.9299 . The final number of blocks was 5 that ensure the mean propensity score was not different for beneficiary and non-beneficiary in each block. The balancing property was satisfied, which implies that the beneficiary and non-beneficiary household were balanced in the similar propensity scores base on similar observed characteristics. After imposing common support condition, a small number of non-beneficiary households have been excluded ( 2 households). Moreover, the quality of the estimated score of matching was evaluated by visual assessment presenting in Figure 1. For that purpose, histograms of estimated propensity scores for VGD beneficiary and non-beneficiary household are presented in Figure 1 separately. The Figure 1 shows that the distributions of the estimated propensity scores for non-beneficiary households skewed to the left in (a) and beneficiaries to the right in (b). These results imply that it is very logical to consider the non-beneficiary as the program non-participant and beneficiary as the program participant based on estimated propensity score. The estimated propensity scores show that there were no perfectly predicted observations, either 0 or 1 for propensity score. The propensity score 0 means the households never receive the program benefit while 1 indicates always receive the program benefit.

Therefore, the region of common support is larger enough. The larger common support implies that strong causation of the program impact that was expected for this study. Moreover, larger common support indicates both groups are comprehensively comparable on the basis of the estimated propensity score. 


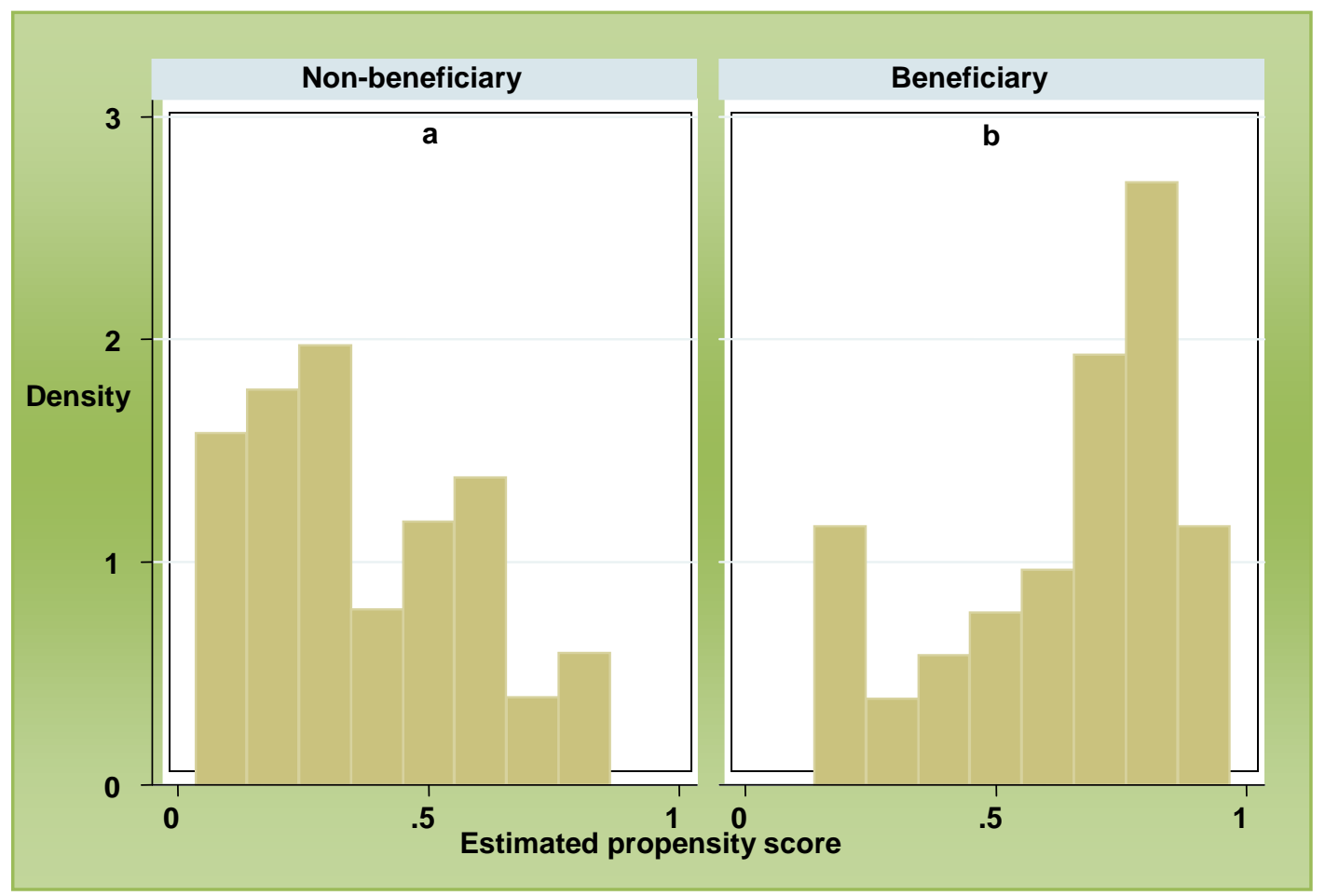

Figure 1: Propensity score distribution after matching by household types

\subsection{Households Spending Patterns}

Household spending means total expenditure by the households on goods and services, and others over a given period of time. Thus, spending pattern depends on some factors like disposable income, marginal propensity to consume, marginal propensity to save, asset, expectation, and others. Keynesian hypothesis asserts that consumption is a stable function of disposable income in the short run. The permanent and life cycle income hypothesis emphasize that consumption is a stable function of income in the long run. Besides these, consumption pattern can be changed by the other factors such as received in-kind transfer or assistance, motivation or imposing a condition to save, increase intention to run a petty trading and others. To analyze the spending pattern of the surveyed households, beneficiary and non-beneficiary, the study employs meal frequency, per capita household spending, per capita food and non-food spending. The study reports descriptive statistics, Simpson index, and PSM techniques to measure the household spending pattern.

\subsection{Meal Frequency}

The rural people in Bangladesh at the individual or household level generally take meals three times a day. To them, food security means to access or achieve this required food without considering dietary composition. Table 7 illustrates the meal frequency taken by the households a day. Among the respondents, 23.66 percent consumed meals two times a day. On the other hand, 76.34 percent consumed meals three times a day. The estimated result pointed out that 98.73 percent of beneficiary consumed meals three times a day, while among the non-beneficiary it was about 54 percent who have three meals a day. In particular, the number of households among beneficiary who could afford to consume three meals a day increased substantially at the time of the survey. With the NNM technique, average impact of taking meals a day on beneficiary households is 0.43 that is statistically significant at the 1 percent level $(t=4.42)$. More specifically, the average mean difference of the number of taking meal a day between beneficiary and non-beneficiary households is 0.43 . This result implies that VGD program facilitates the beneficiary household to increase having meals a day so that they could live without starving.

Table 7: Number of meals taken by households in a day

\begin{tabular}{|l|l|l|l|l|}
\hline \multirow{2}{*}{ Number of meals a day } & \multicolumn{2}{|c|}{ Tousehold Type } & Total households & ATT \\
\cline { 2 - 3 } & Non-beneficiary (\%) & Beneficiaries (\%) & & $(\mathrm{NNM})$ \\
\hline 2 times & $73(45.91 \%)$ & $2(1.27 \%)$ & $75(23.66 \%)$ & $0.43(\mathrm{t}=4.42)$ \\
\hline 3 times & $86(54.09 \%)$ & $156(98.73 \%)$ & $242(76.34 \%)$ & \\
\hline Total & $159(100 \%)$ & $158(100 \%)$ & $317(100 \%)$ & \\
\hline
\end{tabular}

Note: ATT = Average Treatment Effect on number of meals. NNM = Nearest-Neighbour Matching. 


\subsection{Per Capita Expenditure}

Table 8 illustrates the impact of the VGD program on household per capita expenditure based on household actual expenditure. Actual expenditure means the expenditure that has been spent on different goods and services for consumption purpose. Average program effect on per capita expenditure is estimated by PSM method using different matching techniques so that estimated impact would be robust. However, the number of beneficiary and non-beneficiary given in the table 4.8 refer to the actual matches with the different matching techniques based on the estimated propensity score, not surveyed beneficiary and non-beneficiary.

Participation in the program leads to a statistically significant increases in per capita expenditure. Specifically, the prog ram participation does have a significant positive impact on household per capita expenditure with different matching method. However, the average treatment effect of the program on per capita expenditure for the program participants is BDT133.57 with NNM method. Another way it can be mentioned that the program impact for the participation in the program on per capita household expenditure is eight percent. The impact is significant at the one percent level $(t=8.84)$.

Table 8: Impact of VGD program on per capita expenditure per month (in BDT)

\begin{tabular}{|l|l|l|l|l|l|l|}
\hline $\begin{array}{l}\text { Matching } \\
\text { technique }\end{array}$ & $\begin{array}{l}\text { Number of } \\
\text { beneficiary }\end{array}$ & $\begin{array}{l}\text { Number of } \\
\text { Non-beneficiary }\end{array}$ & Common support cond. & $\begin{array}{l}\text { Average } \\
\text { effect(ATT) }\end{array}$ & Std.err & t-value \\
\hline NNM & 158 & 77 & Yes & 118.57 & 17.42 & 6.80 \\
\hline SM & 158 & 151 & Yes & 127.71 & 9.88 & 12.92 \\
\hline RM(0.01) & 131 & 144 & Yes & 130.79 & 10.57 & 12.36 \\
\hline KM(re100) & 158 & 157 & Yes & 122.34 & 9.88 & 12.37 \\
\hline
\end{tabular}

The result also shows that average impact is almost same and significant at the one percent level with the SM and RM method. The program impact on household per capita expenditure is BDT 127.93 and BDT 130.83 with SM and RM technique, respectively. In terms of percentage, the program impact is nine percent with SM method. The same result is found with RM technique. The impact both is significant at the one percent level with $t=12.92$ and $t=12.36$, respectively. In absolute term, NNM method shows the largest impact (BDT 118.57) and KM method shows the smallest (BDT 122.43) impact on per capita expenditures. However, estimated results with alternative matching techniques assert that program impact on household per capita expenditure is positively significant on an average.

\subsection{Per Capita Food Expenditure}

From the earlier section, the study found that household's per capita expenditure among beneficiary is significantly higher than non-beneficiary which is considered as program impact. The study also indented to decompose the program impact into food and non-food expenditure. This decomposition is accurate for understanding the larger impact whether on food or non-food expenditure. Table 9 depicts the estimated impact on household per capita food expenditure using different matching techniques. The results show that the program beneficiary does have a significant negative impact on household per capita food expenditure with different matching methods. The average program impact on per capita food expenditure for program beneficiary is BDT-53.06 with the NNM technique that is significant at the one percent level $(t=-3.54)$. In terms of percentage, the program decreases the per capita food expenditure by 4.2 percent. The result also shows that BDT 49.14 decrease in per capita food expenditure with the SM method because of participation in the VGD program (4.2 percent). This result is significant at the one percent level $(t=-6.90)$. Using $R M$ method, the program impact on household per capita food expenditure is BDT-48.44. In terms of percentage, the program decreases the per capita food expenditure by 4.2 percent. This impact is significant at the one percent level $(t=-6.22)$. According to $\mathrm{KM}$ method, the program impact on per capita food expenditure is BDT-52.69. This means that the program reduces the per capita food expenditure of beneficiary household by 4.6 percent compare to the per capita food expenditure of non-beneficiary household. This impact is also significant at 1 percent level $(t=-5.94)$. The results indicate that program beneficiaries reduce their food expenditure compare to non-beneficiaries' expenditures. As the beneficiary households were receiving in-kind (rice) transfer before starting the survey, they intended to expend less on food expenditure in one sense. In another sense, due to increase in income as indirect effect of the program the beneficiary household intended to decrease food expenditure. This consumption behaviour of the households indicates that the well-known Engel' law works well.

Table 9: Impact of VGD program on per capita food expenditure per month (in BDT)

\begin{tabular}{|l|l|l|l|l|l|l|}
\hline Matching technique & Number of beneficiary & $\begin{array}{l}\text { Number of non- } \\
\text { beneficiary }\end{array}$ & $\begin{array}{l}\text { Common } \\
\text { support cond. }\end{array}$ & $\begin{array}{l}\text { Average effect } \\
\text { (ATT) }\end{array}$ & Std.erro & t-value \\
NNM & 158 & 77 & Yes & $-53.06^{\star \pi \times}$ & 14.95 & -3.54 \\
\hline SIM & 158 & 157 & Yes & $-49.14^{\star \star \star}$ & 7.11 & -6.90 \\
\hline RM(0.01) & 131 & 144 & Yes & $-47.96^{\star \pi \times}$ & 7.71 & -6.22 \\
\hline
\end{tabular}




\begin{tabular}{|l|l|l|l|l|l|l|}
\hline KM(re100) & 158 & Yes & & $-52.69^{* \times 1}$ & 8.86 & \\
\hline
\end{tabular}

Note: ATT = Average Treatment Effect, NNM = Nearest-Neighbour Matching, SM=Stratification Matching, RM=Radius Matching, $\mathrm{KM}=$ Kernel Matching. ${ }^{*},{ }^{* *}$ and ${ }^{* * *}$ indicated significant at $10 \%, 5 \%$ and $1 \%$ level, respectively.

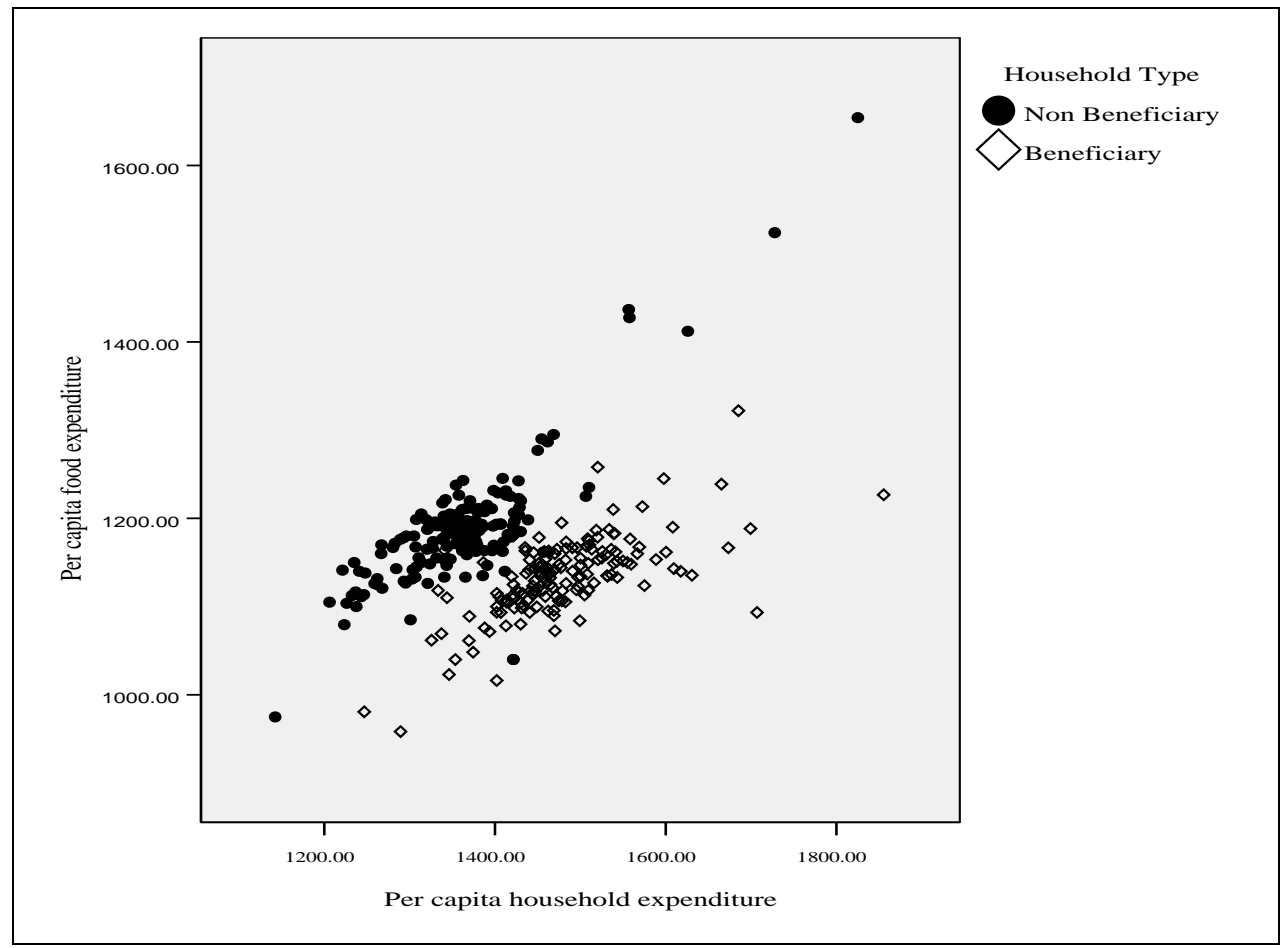

\section{Figure 2: Scatter plot for food consumption against household consumption expenditure per capita by the household type}

Figure 2 depicts food consumption per capita against household expenditure per capita for beneficiary and non-beneficiary households. The data points are densely accumulated to the right-upward for the beneficiary. The figure illustrates typical picture to understand the essential underlying relationships between per capita food expenditure and household per capita expenditure for beneficiary household. This means that food expenditure per capita rises slowly when per capita household spending rises. However, the data points are densely accumulated to the left-up and moving up-ward for nonbeneficiary household. The trend implies that food expenditure per capita of non-beneficiary household rises rapidly when per capita household spending rises.

\subsection{Per Capita Non-food Expenditure}

Expenditure on non-food is another part of total household expenditure. Generally, poorer family spends a larger share of its total expenditure on food and smaller share on non-food expenditure such as clothing, housing, education, health and others. On the other way, expenditure on non-food consumption generally rises rapidly with the income increases.

Table 10 illustrates the average impact of the VGD program on household per capita non-food expenditure with the different matching techniques. The result shows that BDT 171.64 increases in per capita non-food expenditure for beneficiaries with NNM method. This impact is statistically significant at the one percent level $(t=18.52)$. With the SM method, the average treatment effect is BDT176.85. The maximum treatment effect is BDT178.72 with RM method. KM shows that the treatment effect is BDT175.03. The estimated impact is statistically significant at the one percent level. In another way, the program impact on per capita household non-food expenditure are 70.6 percent, 72.8 percent, 72.3 percent, and 72 percent with NNM, SM, RM, and KM method, respectively.

Table 10: Impact of VGD program on per capita non-food expenditure per month (in BDT)

\begin{tabular}{|c|c|c|c|c|c|c|}
\hline Matching technique & Number of beneficiary & $\begin{array}{c}\text { Number of } \\
\text { non- } \\
\text { beneficiary }\end{array}$ & $\begin{array}{c}\text { Common } \\
\text { support } \\
\text { cond. }\end{array}$ & $\begin{array}{c}\text { Average } \\
\text { effect (ATT) }\end{array}$ & Std.erro & t-value \\
\hline NNM & 158 & 77 & Yes & $171.64^{* * *}$ & 8.87 & 19.34 \\
\hline SM & 158 & 157 & Yes & $176.85^{* * *}$ & 5.74 & 30.77 \\
\hline RM(0.01) & 131 & 144 & Yes & $178.72^{* * *}$ & 6.91 & 25.86 \\
\hline KM(re100) & 158 & 157 & Yes & $175.03^{* * *}$ & 5.07 & 34.46 \\
\hline
\end{tabular}


Note: ATT = Average Treatment Effect, NNM = Nearest-Neighbour Matching, SM=Stratification Matching, $\mathrm{RM}=$ Radius Matching, $\mathrm{KM}=$ Kernel Matching. * , ** and ${ }^{* * *}$ indicated significant at $10 \%, 5 \%$ and $1 \%$ level, respectively.

Figure 3 portrays non-food consumption expenditure per capita against household expenditure per capita for beneficiary and non-beneficiary households. The data points are densely accumulated to the upper-ward for the beneficiary. The figure illustrates typical picture to understand the important underlying relationships between per capita non-food expenditure and household per capita expenditure of beneficiary and non-beneficiary household. This means that nonfood expenditure per capita rises rapidly among beneficiary when per capita household spending rises. However, the data points are densely accumulated to the lower and concentrated parallel to the horizontal axis for non-beneficiary household. This trend implies that non-food expenditure per capita rises slowly for non-beneficiary when per capita household spending rises. Moreover, the results imply that beneficiary households' welfare increases as their non-food expenditure increases. It might be considered as program impact with increase in income.

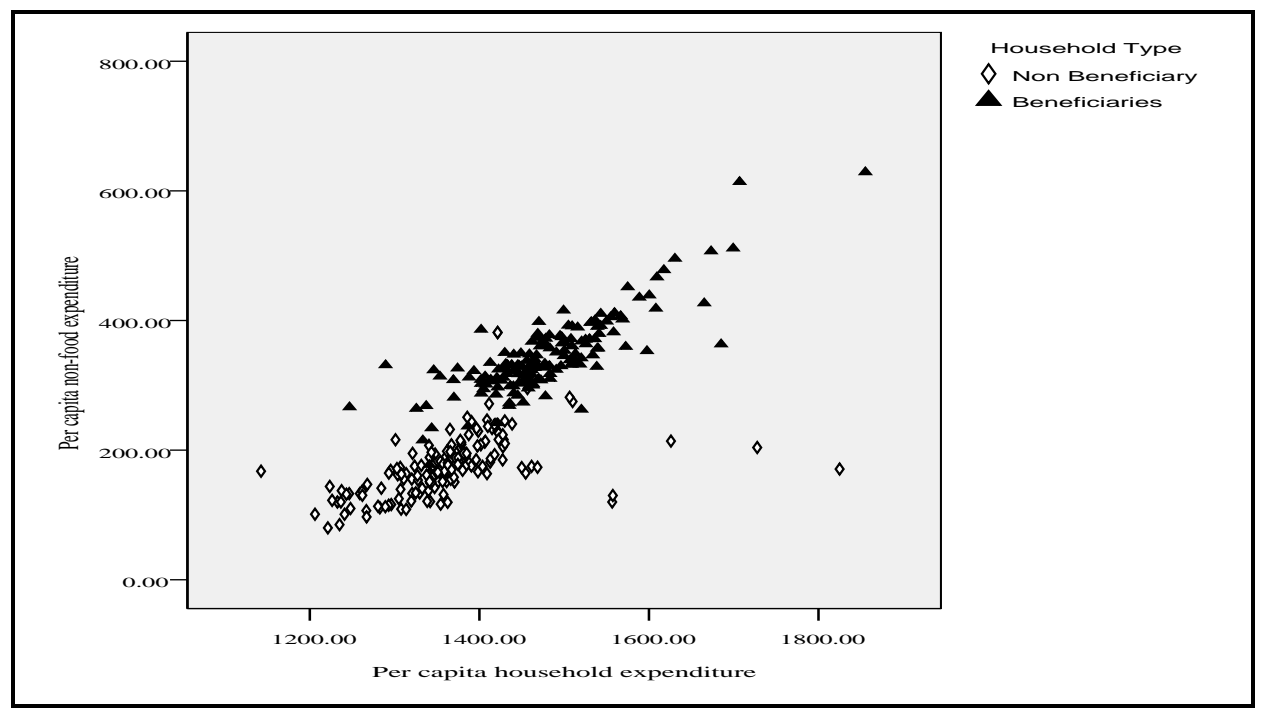

Figure 3: Scatter plot for non-food consumption against household consumption expenditure per capita by the household type

\subsection{Consumption Variability}

By decomposing the per capita household expenditure into per capita food and non-food expenditure, the earlier results show that the average impact on per capita food expenditure of the beneficiary households decreased significantly applying NNM, SM, RM, and KM. On the other hand, the average impact on per capita non-food expenditure was significantly positive with all matching methods. This result implies that as the beneficiaries were receiving in-kind benefit (rice) on a monthly basis, the program helps the beneficiary households improve food deficiencies and move to non-food items.

To justify this result, the study also applied Simpson Index (SI) that is usually known as a diversity index to estimate consumption diversity. To assess the consumption diversity of households, SI was calculated using the survey data for beneficiary and non-beneficiary. Table 11 shows the estimated results into three classes and overall for beneficiary and non-beneficiary households. The proportion of the non-beneficiary households is 63.52 percent to the SI value less than 0.25 . With the same value, the proportion of the beneficiary households is only 0.64 percent. But the proportion of the nonbeneficiary households with SI value $0.25-0.5$ is 34.84 percent. On the other hand, with the same value the proportion of beneficiary is 95.56 percent that is three times higher than the non-beneficiary households. Moreover, with more than 0.5 IS value the proportion of non-beneficiary and beneficiary households are only 0.64 percent and 3.80 percent, respectively.

The overall value of $\mathrm{SI}$ is 0.4086 and 0.2383 for beneficiary and non-beneficiary household, respectively. As the SI value for beneficiaries is higher than non-beneficiary, this means that VGD program helps to improve food diversity for the beneficiaries. Though the SI value for beneficiary is higher, it is below 0.5. This implies that large part of household spending goes for food spending. But these households do not go on a balanced diet even. Many households in rural Bangladesh consider a full plate of rice a full meal. They failed to consume more items due to limited affordability. In addition, they are not aware of importance of balanced dietary diversity.

Table 11: Consumption diversity index of beneficiary and non-beneficiary households

\begin{tabular}{|l|l|l|l|l|l|l|}
\hline \multirow{2}{*}{ Simpson Index(SI) } & \multicolumn{3}{|l|}{ Non-beneficiary households } & \multicolumn{3}{l|}{ Beneficiary households } \\
\cline { 2 - 7 } & Frequency & percent & Cum. & Frequency & percent & Cum. \\
\hline$<0.25$ & 101 & 63.52 & 63.52 & 01 & 0.64 & 0.64 \\
\hline
\end{tabular}




\begin{tabular}{|l|l|l|l|l|l|l|}
\hline $0.25-0.5$ & 57 & 35.84 & 99.36 & 151 & 95.56 & 96.20 \\
\hline$>0.5$ & 01 & 0.64 & 100 & 06 & 3.80 & 100 \\
\hline Overall value & 0.2383 & & 0.4086 \\
\hline
\end{tabular}

\section{Conclusion and policy implications}

The study object was to analysis the role of the VGD program on beneficiary households to improve the consumption diversity over the benefit cycle. Descriptive statistics, SI, and PSM method with NNM, RM, SM, and KM techniques were used to analyze the survey data on that purposes. Beyond the demographic data, the major outcome variables were meal frequency, food and non-food consumption per capita. Based on the survey data, it can be mentioned that the program contributes to the improvement of the household's well being. The data revealed that the program contribute to increase the meal frequency among the beneficiary respondents. In particular, the number of households among beneficiary who could afford to consume three times meal a day increased substantially at the time of the survey.

Participation in the program leads to statistically significant increase in per capita expenditure. Specifically, the program participation does have a significant positive impact on household per capita expenditure with different matching method. In addition, the program beneficiary does have a significant positive impact on household per capita non-food expenditure with different matching methods. This means that non-food expenditure per capita rises rapidly when per capita household spending rises. The results imply that beneficiary households' welfare increases as their per capita expenditure increases along with non-food expenditure increases. It might be considered as program impact with increase in income. In addition, the study found that the SI value for beneficiary household is higher than non-beneficiary household. This finding indicates that VGD program helped improve consumption diversity for the beneficiary household. This situation requires that the program beneficiaries could increase. Consequently, the total demand in the economy will increase. Finally this could enhance the economic growth.

\section{References}

Abebaw, D., Fentie, Y., \& Kassa, B. 2010. "The impact of a food security program on household food consumption in Northwestern Ethiopia: A matching estimator approach" in Food Policy, Vo.35, No.4, 286-293.

Afrad, M. S. I., Ferdous, S., Muttaleb, M. A., \& Rahman, M. M. 2012. "Impact of Vulnerable Group Development Program on Food Security in Kushtia Sadar Upazila of Bangladesh" in Journal of Food Science and Engineering”, Vol.2, No,9.

Ahmed, A. U., Quisumbing, A. R., Nasreen, M., Hoddinott, J. F., \& Bryan, E. 2009. Comparing food and cash transfers to the ultra poor in Bangladesh. Washington DC: IFPRI.

Angrist, J. D. 2001. "Estimation of limited dependent variable models with dummy endogenous regressors", in Journal of Business \& Economic Statistics, Vol.19, No.1.

FD. (2011). Bangladesh Economic Review-2011. Dhaka: Finance Division, Ministry of Finance, Government of The People's Republic of Bangladesh.

Galasso, E., \& Ravallion, M. 2005. "Decentralized targeting of an antipoverty program", in Journal of Public economics, Vol. 89, No. 4, 705-727.

Gentilini, U., \& Webb, P. 2008. "How are we doing on poverty and hunger reduction? A new measure of country performance", in Food Policy, Vol. 33, No.6, 521-532.

Haughton, J. H., \& Khandker, S. R. 2009. Handbook on poverty and inequality: World Bank Publications.

Heckman, J. J., Ichimura, H., \& Todd, P. 1998. "Matching as an econometric evaluation estimator", in The Review of Economic Studies, Vol.65, No.2, 261-294.

Heckman, J. J., LaLonde, R. J., \& Smith, J. A. 1999. "The economics and econometrics of active labor market programs", in Handbook of labor economics, Vol.3, 1865-2097.

Hope, R. 2007. "Evaluating social impacts of watershed development in India", in World Development, Vol.35, No.8, 14361449.

Jalan, J., \& Ravallion, M. 2003. "Estimating the benefit incidence of an antipoverty program by propensity-score matching", in Journal of Business \& Economic Statistics, Vol.21, No.1, 19-30.

Khandker, S. R., Koolwal, G. B., \& Samad, H. A. 2010. Handbook on impact evaluation: quantitative methods and practices: World Bank Publications.

Matin, I., \& Hulme, D. 2003. "Programs for the Poorest: Learning from the IGVGD Program in Bangladesh", in. World Development, Vol.31, No.3, 647-665.

Mendola, M. 2007. "Agricultural technology adoption and poverty reduction: A propensity-score matching analysis for rural Bangladesh", in Food Policy, Vol.32,No.3, 372-393. 


\section{ISSN $2321-1091$ \\ Volume $11 \mathrm{Number} 1$ \\ Journal of Social Sciences Research}

Ninno, C. D., \& Dorosh, P. 200. "Impacts of in-kind transfers on household food consumption: Evidence from targeted food programmes in Bangladesh", in The Journal of Development Studies, Vol.40, No.1, 48-78.

Ravallion, M. 2007. "Evaluating anti-poverty programs", in Handbook of development economics, Vol. 4, 3787-3846.

Raza, W. A., \& Ara, J. 2012. "Grant Based Approach to Poverty Reduction: Evidence from Bangladesh", in OIDA International Journal of Sustainable Development, Vol.3, No.6, 37-56.

Rhman, H. Z., \& Choudhury, L. A. 2012. Social Safety Nets in Bangladesh (Vol. 2). Dhaka: Power and Participation Research Centre.

Rosenbaum, P. R., \& Rubin, D. B. 1983. "The central role of the propensity score in observational studies for causal effects", in Biometrika, Vil.70, No.1, 41-55.

Rosenzweig, M. R. 1988. "Risk, implicit contracts and the family in rural areas of low-income countries", in The Economic Journal, Vol.98, No.393, 1148-1170.

Sheheli, S. 2012. "Improving livelihood of rural women through income generating activities in Bangladesh", in Berlin, Humboldt Universität zu Berlin, Diss., 2012. 